\title{
Segurança em rodovias inseridas em áreas urbanas na região sul do Brasil
}

Safety in highways within urban areas in the southern region of Brazil

Cássio Leandro do Carmo[a] [D , Archimedes Azevedo Raia Junior[a] (1)

[a] Universidade Federal de São Carlos (UFSCar), São Carlos, SP, Brasil

Como citar: Carmo, C. L., \& Raia Junior, A. A. (2019). Segurança em rodovias inseridas em áreas urbanas na região sul do Brasil. urbe. Revista Brasileira de Gestão Urbana, 11, e20170182. https://doi.org/10.1590/2175-3369.011. e20170182.

\section{Resumo}

Este artigo analisa a segurança viária das rodovias federais inseridas em áreas urbanas na região Sul do Brasil. Procura avaliar a ocorrência de vítimas, com base nos registros da Polícia Rodoviária Federal (PRF), em conjunto com as condições do pavimento, da geometria viária e da sinalização de trânsito, de acordo com a metodologia da Confederação Nacional do Transporte (CNT). Trechos urbanos críticos foram destacados, com o uso de um programa de geoprocessamento, e, para a delimitação dos acidentes, foram utilizados conceitos fundamentados na abordagem do Sistema Seguro (Safe System), que considera que os acidentes de trânsito, quando ocorrerem, não devem provocar vítimas graves e fatais. Quando se levam em conta os óbitos e as vítimas com lesões graves, os trechos urbanos das rodovias federais na região Sul estavam entre os mais perigosos do Brasil. A maior parte das rodovias em áreas urbanas foi classificada como "boa" no que se refere ao estado de conservação, mas vários segmentos concentraram grande número de vítimas, principalmente de motocicletas. Como destaque negativo, São José, em Santa Catarina, apresentou o trecho mais crítico. Dos segmentos com grande acidentalidade, quase todos estavam próximos a grandes aglomerações urbanas ou a capitais regionais, devido, provavelmente, ao grande número de deslocamentos gerados por atividades socioeconômicas.

Palavras-chave: Segurança viária. Sistema seguro. Rodovias. Áreas urbanas.

\section{Abstract}

This paper analyzes the road safety of federal highways within urban areas in the Southern region of Brazil. It seeks to evaluate the occurrence of victims, based on the records of the Brazilian Federal Highway Police (PRF), with the conditions of the pavement, the geometry, and the traffic signs, according to the methodology of the National Transportation Confederation (CNT). Critical urban stretches are highlighted in a geoprocessing program and concepts based on the Safe System approach are used for the delimitation of accidents. This approach considers that traffic accidents when they occur, should cause neither death nor serious injury. Considering deaths and victims with serious injuries, urban stretches of federal highways in Southern Brazil are among the most dangerous of Brazil. Most highways in urban areas were classified as being in good condition; however, several of them concentrated a large number of victims, 
primarily motorcyclists. As a negative highlight, São José, in Santa Catarina State, presented the most critical section. Of the stretches with great accidentality, nearly all were close to large urban agglomerations or to regional capitals, probably due to a large number of movements generated by socioeconomic activities.

Keywords: Road safety. Safe system. Highways. Urban areas.

\section{Introdução}

A segurança viária é um dos principais objetivos da engenharia de tráfego. Os deslocamentos cotidianos devem ser seguros, realizados de forma confortável e em um tempo justo. Uma mobilidade urbana sustentável somente será completa quando houver baixos índices de acidentes e números reduzidos de vítimas no trânsito, principalmente com lesões graves e fatais. Essa segurança tem se tornado um desafio cada vez maior nos países em desenvolvimento. 0 crescimento do transporte individual e motorizado, aliado à precária infraestrutura urbana e à deficiência no transporte coletivo na maioria das cidades, torna insustentável a boa gestão no trânsito. No Brasil, na última década, o número de automóveis triplicou, com quase 100 milhões de veículos atualmente (Denatran, 2017).

Os municípios não têm sido capazes de gerir esse aumento da frota. As rodovias inseridas nesses ambientes, então, tornam-se a alternativa para deslocamentos mais rápidos, que fujam dos congestionamentos cotidianos. São também a ligação, muitas vezes única, entre cidades vizinhas, em aglomerações urbanas cada vez mais próximas. Assim, nessas rodovias, antes exclusivamente rurais, o tráfego urbano e o de passagem se confundem. Automóveis e motocicletas com diferentes velocidades misturam-se aos pedestres, em verdadeiras "avenidas", o que causa conflitos e acidentes de trânsito. Mais da metade dos acidentes em rodovias federais acontece nos segmentos urbanos. Também nesses trechos estão mais de $40 \%$ das vítimas graves e dos óbitos de todas as rodovias federais.

Contudo, os mais modernos sistemas de gestão da segurança viária buscam garantir uma situação de zero vítima fatal ou com graves lesões em razão dos acidentes de trânsito. 0 programa de segurança viária sueco Visão Zero, por exemplo, considera inadmissível que pessoas morram ou fiquem seriamente feridas nos acidentes. De acordo com essa filosofia, quanto mais segura for a via, maior será a mobilidade oferecida. E essa mobilidade urbana, segura e sustentável, tornou-se um dos maiores problemas na gestão urbana. Para que os deslocamentos sejam realizados em áreas urbanas cada vez maiores, com segurança, conforto e em um tempo adequado, é necessário que haja infraestrutura e gestão de transportes apropriadas.

Este artigo tem como objetivo analisar a acidentalidade viária nas rodovias federais inseridas em áreas urbanas na região Sul do Brasil, bem como verificar a relação das condições de infraestrutura com o número de vítimas graves e fatais. Especificamente, busca conhecer as áreas urbanas com maior concentração de ocorrências e investigar a contribuição das variáveis geometria, pavimentação e sinalização para os segmentos mais críticos.

\section{Método}

Para a realização do trabalho, foram inicialmente obtidos dados de vítimas de acidentes em rodovias federais, entre 2010 e 2014, com a Polícia Rodoviária Federal (PRF, 2015). A malha rodoviária federal foi disponibilizada pelo Departamento Nacional de Infraestrutura de Transporte (DNIT, 2014), de acordo com o Sistema Nacional de Viação (SNV).

Neste estudo, a classificação da gravidade da lesão e do uso do solo como urbano esteve a critério do policial responsável pelo registro das ocorrências. 0 número de óbitos e de vítimas gravemente feridas foi distribuído a cada $10 \mathrm{~km}$, em todas as rodovias federais da região Sul, para a obtenção dos trechos urbanos críticos. Cada segmento inclui os acidentes do seu quilômetro inicial até o quilômetro final do 
trecho, excluindo as vítimas nesse ponto. Assim, por exemplo, o segmento de 0 a $10 \mathrm{~km}$ inclui o número de vítimas a partir do quilômetro zero até o quilômetro 9,9, máxima aproximação dos dados fornecidos pela Polícia Rodoviária Federal.

As rodovias que apresentaram mais vítimas foram selecionadas, e, então, foram abordados os segmentos e as áreas mais inseguras. Com a utilização da Pesquisa de Rodovias da Confederação Nacional do Transporte (CNT), foi avaliada a infraestrutura viária desses trechos com relação às condições de geometria, sinalização e pavimentação. 0 uso de um programa de geoprocessamento e de imagens aéreas propiciou uma melhor análise e visualização, além do destaque das áreas e dos trechos com maior acidentalidade.

\section{A segurança viária mundial e brasileira}

Em 2009, o relatório da Organização Mundial da Saúde (WHO, 2009) Global status report on road safety: time for action mostrou que mais de 1,2 milhão de pessoas morria, em média, a cada ano nas vias urbanas, rodovias e estradas mundiais, e que entre 20 e 50 milhões sofriam lesões provocadas em acidentes de trânsito.

O relatório Global status report on road safety 2013: supporting a decade of action (WHO, 2013) mostrou que houve, em 2010, 1,240 milhão de mortes no trânsito em todo o mundo, número similar ao dos anos anteriores, embora tenha havido um aumento do número de veículos no mundo. Segundo o relatório de 2013, a taxa de mortalidade em acidentes de trânsito no mundo correspondeu a 18 mortes por grupo de 100 mil pessoas. Entretanto, países em desenvolvimento apresentaram taxa média mais elevada, de 20,1 mortes por 100 mil pessoas, enquanto, nos países desenvolvidos, a taxa foi de 8,7 óbitos por 100 mil pessoas.

No Brasil, o Ministério da Saúde (Brasil, 2015) apontou 44.812 vítimas fatais em acidentes de trânsito em 2012. Com uma população estimada de 199.242.462 habitantes pelo Instituto Brasileiro de Geografia e Estatística para o ano de 2012 (IBGE, 2015), o país apresentou uma taxa de 22,5 mortes por 100 mil habitantes, maior que a média dos países em desenvolvimento.

De acordo com a WHO (2013), 80\% das mortes em acidentes de trânsito ocorreram em países com médio desenvolvimento, que contam com $72 \%$ da população mundial, mas somente $52 \%$ dos veículos registrados no mundo. Isso indica um alto índice de mortes no trânsito em relação ao nível de motorização. No Brasil, Bastos et al. (2012) estimaram os índices de mortes em acidentes de trânsito por bilhão de quilômetros percorridos (IMBQ) pela frota de veículos motorizados, de 2004 a 2009. Os resultados obtidos evidenciaram uma significativa correlação entre os índices de mortes nos Estados e o Produto Interno Bruto (PIB) per capita: em geral, quanto menor o PIB per capita, ou seja, Estado com menos desenvolvimento econômico, maior o IMBQ. Para os autores, esses dados deixam claro a forte relação entre a segurança viária e o nível de desenvolvimento local.

Por causa do grave problema da acidentalidade viária, principalmente nos países em desenvolvimento, a Organização das Nações Unidas instituiu a Década de Ação pela Segurança no Trânsito 2011-2020, com objetivo de estabilizar e reduzir a previsão do número de vítimas (UN, 2010). 0 objetivo 3, da Agenda 2030 para o Desenvolvimento Sustentável, estabelece como meta, até 2020, a redução pela metade do número de mortes e lesões causadas pelo trânsito em todo o mundo. 0 objetivo 11 procura assegurar a disponibilidade de sistemas de transporte seguros e sustentáveis, com preços acessíveis a todos, além de melhorias na segurança viária, até 2030, como parte integral da Agenda 2030 para o Desenvolvimento Sustentável (UN, 2015).

Os compromissos com a Década de Ação pela Segurança no Trânsito 2011-2020 foram renovados pela Declaração de Brasília, na Segunda Conferência Global de Alto Nível sobre Segurança no Trânsito: Tempos de Resultados, que definiu medidas necessárias para o alcance das metas até o final da década (WHO, 2015). Os planos de ação propostos pela Organização Mundial de Saúde (WHO, 2017), para o alcance dos objetivos estabelecidos pela Década de Ação pela Segurança no Trânsito 2011-2020, são aqueles incluídos em uma abordagem de um Sistema Seguro (Safe System), como os empregados pelos 
programas de segurança viária Visão Zero, na Suécia, e Segurança Sustentável, nos Países Baixos. Os conceitos sobre o Sistema Seguro serão discutidos na próxima seção.

\section{Sistema Seguro em transportes: o programa Visão Zero}

A segurança, de acordo com o programa Visão Zero, é mais importante que a mobilidade, sendo que a segunda sempre deve estar subordinada à primeira (Ferrer, 2017). A mobilidade deve ser suplementar à função de segurança, pois não estão em um mesmo nível, conforme as premissas da filosofia da Visão Zero. Com uma infraestrutura mais segura, maior será a mobilidade oferecida (Raia, 2009).

Muitos países, há cerca de 20 anos, têm aprimorado a segurança no trânsito, com novas condutas em um Sistema Seguro (Safe System) de transportes. Nos Países Baixos, a Segurança Sustentável, que incorpora princípios do Safe System, foi introduzida a partir de 1991. Na Suécia, a Visão Zero foi adotada pelo parlamento sueco a partir de outubro de 1997. Na Nova Zelândia, o lançamento do programa Viagens Mais Seguras foi realizado em 2010. Na Polônia, um programa de segurança viária, elaborado de acordo com o conceito de Sistema Seguro, foi introduzido em 2012. Nos Estados Unidos, mais especificamente em Nova Iorque, em 2014, e em Los Angeles, em 2015, também foi adotada essa nova conduta de gestão de segurança viária. Na Austrália, em 2015, a cidade de Vitória iniciou a campanha Towards Zero, com o objetivo de colocar na agenda comunitária, como princípio ético, que ninguém deveria morrer nas ruas e rodovias em acidentes de trânsito (ITF, 2016).

Segundo a organização intergovernamental International Transport Forum (ITF, 2016), o Sistema Seguro (Safe System) apoia-se em quatro princípios: as pessoas cometem erros que podem levar a acidentes de trânsito; o corpo humano tem uma limitação física para suportar impactos, sem que haja lesões graves; a segurança é uma responsabilidade compartilhada de todos os "atores" do sistema de transportes, que incluem os projetistas, os construtores e os administradores das vias, em conjunto com os usuários do trânsito; todos os elementos do sistema formam uma rede integrada de segurança, na qual se combinarão para a prevenção aos acidentes ou, pelo menos, às lesões graves ou fatais.

Novo paradigma de segurança viária, o programa Visão Zero foi construído de acordo com a ideia de que, se nem todos os acidentes podem ser prevenidos, pode-se evitar, em princípio, a severidade das lesões (Johansson, 2008). Conforme preconizam os princípios de um Sistema Seguro (Safe System), exemplificado na Visão Zero, a geometria e a conservação das rodovias, com pavimentação e sinalização adequadas, além de um bom controle de operação, devem propiciar comportamento e direção seguros para motoristas, passageiros e pedestres. Caso haja imprudência e/ou erros humanos, o sistema deve ser capaz de mitigar as consequências. Em caso de acidentes, então o risco de lesões graves ou de mortes seria reduzido.

A partir da próxima seção, serão analisados trechos urbanos das rodovias federais brasileiras, com maior ênfase à região Sul do Brasil, na qual houve grande número de mortes ou pessoas gravemente feridas em acidentes. Um panorama nacional será apresentado, e, na sequência, os Estados do Paraná, Santa Catarina e Rio Grande do Sul serão abordados.

\section{A segurança viária nas rodovias inseridas em áreas urbanas}

As últimas décadas testemunharam um significativo crescimento da população urbana no Brasil. Em muitos casos, esse aumento esteve associado à expansão urbana, a qual, não raramente, tem ocorrido em áreas inadequadas, nas quais estão incluídos espaços ao longo da infraestrutura rodoviária. Rodovias rurais, que antes ligavam cidades, foram envolvidas pela urbanização e se constituem, agora, na principal e mais rápida via da cidade, sendo, às vezes, a única forma de acesso a uma localidade.

Para Meneses (2001), trechos rodoviários de inserção urbana nas regiões metropolitanas brasileiras, por exemplo, constituem-se em importantes eixos estruturais, submetidos à dinâmica urbana e 
suburbana dessas áreas. Segundo o autor, esses segmentos rodoviários devem atender concomitantemente a diferentes requisitos locais e regionais em condições de segurança, o que leva cada trecho rodoviário inserido em áreas urbanas a ter, portanto, peculiaridades com relação às suas características operacionais, geométricas e socioeconômicas.

Devido a particularidades desses segmentos, trabalhos que envolvem o tema foram desenvolvidos. No Estado do Espírito Santo, Bergamasch (2014) abordou os acidentes de trânsito na Região Metropolitana da Grande Vitória, ocorridos entre 2005 e 2013. Com a utilização de técnicas de geoestatística e de geoprocessamento, o autor identificou áreas de concentração dos acidentes, divididos de acordo com sua classificação, e observou um aumento da quantidade e das áreas de ocorrência na região durante o período estudado. Lima et al. (2008) também avaliaram os fatores condicionantes da gravidade dos acidentes de trânsito, em especial os que envolveram pedestres, em trechos da BR-116, em São Paulo, além da BR-324, na Bahia. Encontraram uma série de problemas, como acostamentos deficientes, falhas na manutenção da pavimentação, geometria inadequada da via e problemas de drenagem na via. Com relação à infraestrutura para os pedestres nos trechos urbanos, as condições de travessia, em geral, eram precárias, com algumas exceções. Carmo \& Raia (2016) investigaram a segurança viária em segmentos urbanos das rodovias federais no Estado de São Paulo e constataram que, apesar de classificados como "bom" ou "ótimo" no que se refere a padrões da engenharia rodoviária, tais segmentos apresentavam números consideráveis de acidentes. Encontraram que houve um grande número de acidentes fatais de pedestres, apesar de os atropelamentos terem sido em menor número, como o que ocorreu na BR-116 e na BR-381.

No Nordeste do Brasil, além do trabalho de Lima et al. (2008) na BR-324 (Bahia), Alburquerque et al. (2015) estudaram as relações entre a acessibilidade, analisada por meio da teoria da sintaxe espacial, e os acidentes de trânsito ocorridos até o ano de 2011, no trecho entre os quilômetros 17,5 e 28,1, da BR-230, que passa pela cidade de João Pessoa (PB). Os trechos críticos e susceptíveis a acidentes foram aqueles mais integrados à cidade (de acordo com o maior valor de integração sintático-espacial) e os que minimizavam a distância dos percursos (com menores valores sintáticos para a profundidade média). 0 trecho mais crítico apontado foi entre os quilômetros 25 e 27, em uma área com concentração de polos geradores de tráfego, além de bairros residenciais.

Velloso \& Jacques (2012) afirmam que, embora sejam classificadas como rurais, rodovias que atravessam áreas urbanas possuem características que são típicas de ruas e avenidas urbanas, tais como alto número de pontos de acesso e grande quantidade de pedestres que caminham por seus acostamentos e as cruzam em qualquer ponto, condições que se assemelham ao ambiente urbano. Em suas pesquisas, Velloso et al. (2008) e Velloso \& Jacques (2012) investigaram os fatores contribuintes para os atropelamentos de pedestres em rodovias inseridas em áreas urbanas do Distrito Federal. Os trabalhos analisaram 120 atropelamentos, inclusive com a investigação das circunstâncias no local logo após os acidentes, e apontaram como causas principais a associação entre a atitude do pedestre e as características de meio ambiente da área urbana.

De acordo com Silva (2006) e Silva \& Ferreira (2008), devido às características dos trechos urbanos das rodovias brasileiras, nitidamente os pedestres que nelas circulam estão entre as maiores vítimas. A rodovia exerce a função de barreira, e os pedestres, já tradicionalmente os menos favorecidos na disputa pelo espaço de circulação, são os mais prejudicados, pois, além de serem mais frágeis perante os veículos motorizados, são impedidos de usufruir plenamente do espaço urbano. Os autores analisaram os impactos das rodovias em áreas urbanizadas na percepção dos pedestres, em especial moradores próximos de um trecho urbano da BR-050, que atravessa Uberlândia/MG. Verificaram que, para os pedestres, com relação à variável "insegurança", o risco de sofrer acidentes estava muito identificado com a velocidade e o volume de veículos da rodovia.

Para Jiang \& Peng (2012), há muitos problemas quando rodovias são usadas como vias urbanas, como ausência de calçadas, poucas facilidades para travessias e impossibilidade em atender ao maior volume de tráfego e aos vários modos de transportes (a pé, por bicicleta e motocicleta). 
De acordo as estatísticas de acidentes do DNIT (2015), com base em dados do Departamento de Polícia Rodoviária Federal (DPRF), foram registrados, no ano de 2014, 169.166 acidentes de trânsito nas rodovias federais, dos quais mais da metade (89.931) ocorreu em áreas urbanas, e, em $37 \%$ deles, nos trechos urbanos, houve feridos ou vítimas fatais. Nos acidentes em rodovias federais inseridas em áreas urbanas, em 2014, das 49.147 vítimas, 11.779 sofreram lesões graves, e 2.461, fatais (PRF, 2015).

De 2010 a 2014, mais de 77 mil pessoas ficaram gravemente feridas ou morreram em acidentes nos segmentos rodoviários urbanos fiscalizados pela Polícia Rodoviária Federal, o que correspondeu a 42,5\% do total para toda a extensão das rodovias federais. Os motociclistas estão entre as maiores vítimas, conforme a Figura 1.

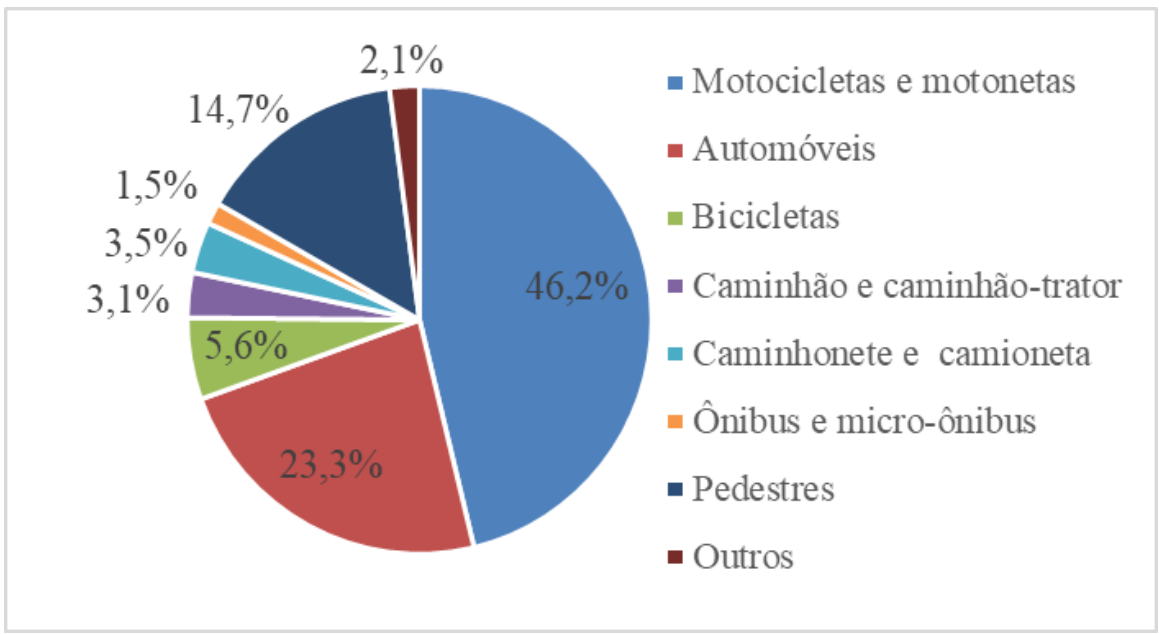

Figura 1 - Óbitos e vítimas com lesões graves, por categorias de veículos, em acidentes nos trechos urbanos de rodovias federais brasileiras, de 2010 a 2014 . Fonte: elaborada pelos autores com base em dados da PRF (2015).

Nos Estados do Paraná, de Santa Catarina e do Rio Grande do Sul, 21.505 pessoas ficaram gravemente feridas ou morreram em acidentes nos segmentos urbanos das rodovias federais brasileiras entre os anos de 2010 a 2014. Trechos urbanos de rodovias federais no Sul do país têm se mostrado, segundo o número de acidentes e de vítimas registrado, bastante inseguros. Esse problema de segurança viária na região também tem sido constatado e estudado há alguns anos.

Diesel (2005), por exemplo, objetivou relacionar os acidentes de trânsito com as ocorrências de precipitações pluviométricas, com a utilização de um Sistema de Informações Geográficas (SIG). Para o desenvolvimento de seu trabalho, fundamentou-se em dados de acidentes ocorridos em oito rodovias federais no Estado de Santa Catarina, que abrangeram os anos de 1998 a 2003, além do volume de veículos, índices pluviométricos e informações das populações dos municípios atravessados pelas rodovias. Em uma das conclusões, Diesel (2005) ressalta que a duplicação do trecho norte da BR-101 não gerou redução de óbitos, em ocorrências de acidentes de trânsito em dias com precipitação pluviométrica. Embora duplicado, dever-se-ia refletir mais profundamente sobre a questão de vias de transporte rápidas cruzando espaços claramente urbanos, de acordo com a autora.

Salvador \& Goldner (2009) analisaram os tipos de acidente de trânsito que ocorreram na BR-101, a partir de dados de acidentes dos anos de 2004 a 2007, em três trechos da rodovia, inclusive nos 23,5 km da rodovia na Grande Florianópolis, duplicados e localizados em áreas urbanas. No trecho urbano, o número de ocorrências passou de 1.322, em 2004, para 1.697, em 2007, aumento que podia estar relacionado ao crescimento do volume de tráfego. Colisões traseira e lateral eram as mais comuns, e o trecho da Grande Florianópolis, por possuir uma concentração populacional em áreas adjacentes, apresentava a maior porcentagem de atropelamentos de pedestres entre os três trechos pesquisados. Peña (2011) pesquisou a segurança viária em interseções entre rodovias federais em Santa Catarina, inclusive com um estudo de caso da interseção entre a BR-116 e a BR-282, no município de Lages. Como 
resultado, encontrou que interseções com índices de volume diário médio anual mais altos apresentaram mais acidentes e com maior gravidade, e aquelas inseridas em meios urbanos implicaram maiores taxas de acidentes.

Segmentos de rodovias que possuem uma concentração populacional em áreas adjacentes foram estudados por Freire (2003), em uma avaliação de um conjunto de projetos de programa de melhorias dessas travessias urbanas em cidades de portes pequeno e médio do Estado do Rio Grande do Sul. A maioria das soluções encontradas envolveu a implantação de rótulas e interseções de acesso principal à cidade, restrições à ultrapassagem com tachões bidirecionais nas rodovias de pistas simples, complementação ou implantação de rua lateral, regulamentação de velocidade limite, instalação de placa de indicação de perímetro urbano, utilização de pavimento diferenciado nos acessos e medidas de proteção aos pedestres. Schmitz \& Goldner (2010) e Schmitz (2011) analisaram segmentos críticos de rodovia com um estudo de caso na BR-285, no Estado do Rio Grande do Sul, em uma malha segmentada em $674,2 \mathrm{~km}$ da rodovia, dos quais 61 trechos eram urbanos. Com o georreferenciamento dos acidentes, as autoras observaram que a maioria deles ocorridos nas áreas urbanas envolveu colisões e atropelamentos, principalmente nas interseções com as vias municipais.

Dada a gravidade do problema nos Estados do Sul do país, verificada na literatura e por meio dos dados oficiais de vítimas de acidentes, o tema é abordado nesta pesquisa. A próxima seção aprofundará o estudo, para cada Estado, em seus trechos críticos e diversas cidades da região. A avaliação dos segmentos será feita de acordo com a Pesquisa CNT de Rodovias (CNT, 2010, 2011, 2012, 2013, 2014).

\section{A insegurança viária em trechos urbanos de rodovias federais na região sul do brasil}

Tendo visto a realidade da insegurança viária em diversas áreas urbanas, foram identificados segmentos críticos das rodovias federais em centros urbanos, nos Estados do Paraná, de Santa Catarina e do Rio Grande do Sul, com a inserção de dados desses trechos em um programa de geoprocessamento para melhor visualização e análise. A realidade brasileira da acidentalidade envolvendo motocicletas também ocorreu na região Sul do Brasil. A Figura 2 ilustra a participação das categorias de veículos e pedestres no número de óbitos e de vítimas com lesões graves nos acidentes em segmentos urbanos das rodovias federais nos Estados do Sul.

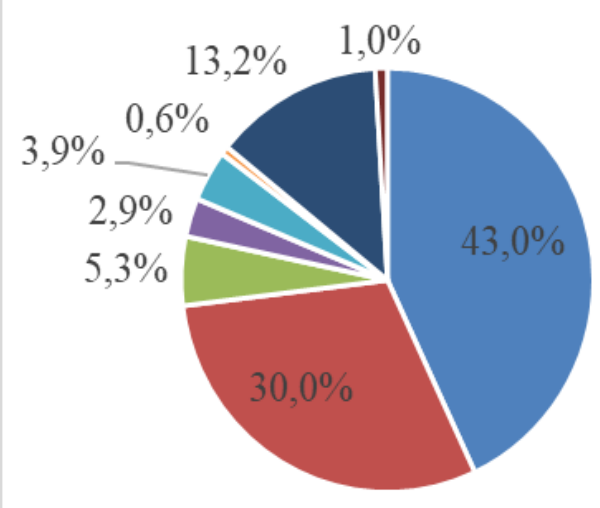

- Motocicletas e motonetas

- Automóveis

- Bicicletas

- Caminhão e caminhãotrator

- Caminhonete e camioneta

- Ônibus e micro-ônibus

Figura 2 - Óbitos e vítimas com lesões graves, por categorias de veículos, em acidentes nos trechos urbanos de rodovias no Sul do Brasil, de 2010 a 2014. Fonte: elaborada pelos autores com base em dados da PRF (2015).

No período de 2010 a 2014, 86\% dos óbitos e das vítimas com graves lesões estavam em acidentes que envolveram motocicletas/motonetas, automóveis e pedestres. Em 3.256 acidentes, houve 3.606 vítimas fatais, das quais 12 estavam em ônibus ou micro-ônibus. A Figura 3 mostra os números de vítimas feridas com gravidade e as fatais, por Estado, durante os cinco anos. 


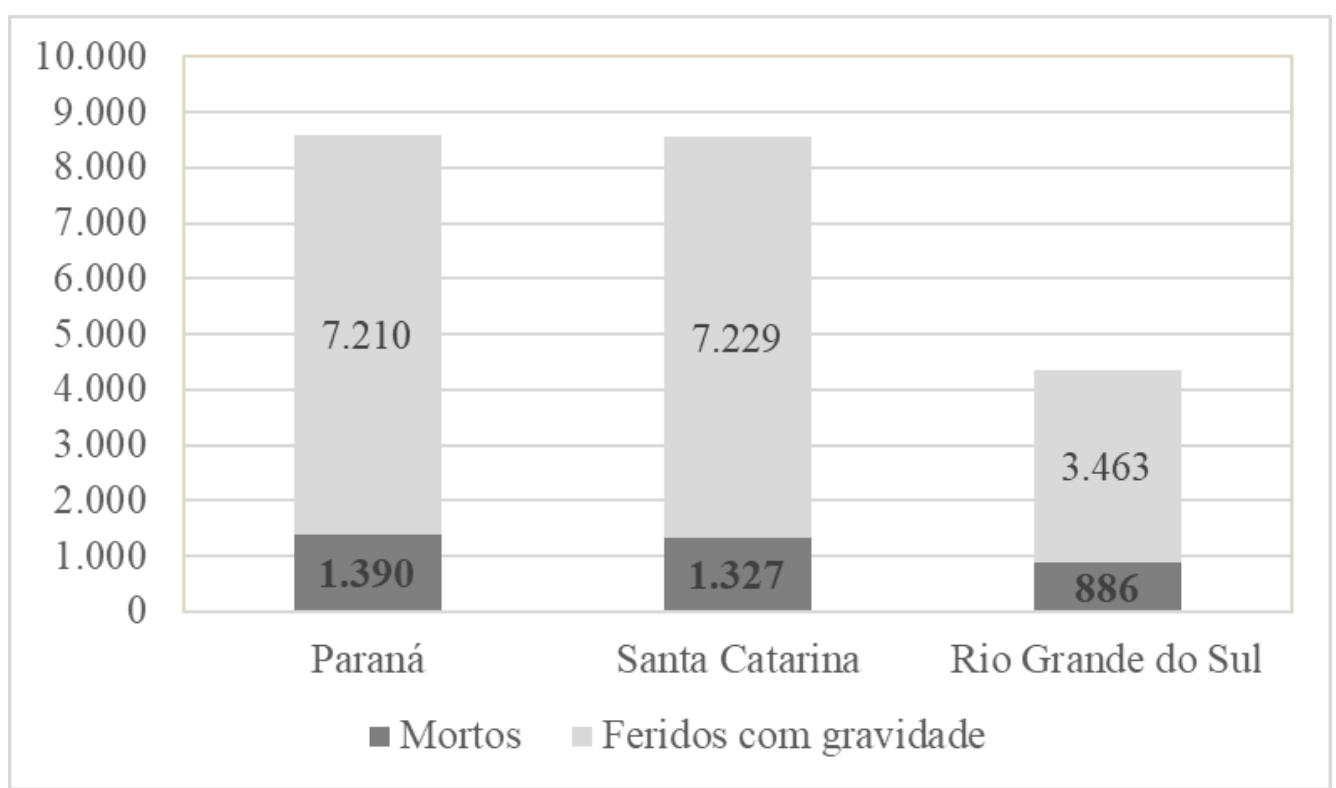

Figura 3 - Vítimas fatais e com lesões graves em acidentes de trânsito nos trechos urbanos de rodovias federais, de 2010 a 2014, nos Estados do Sul do Brasil. Fonte: elaborada pelos autores com base em dados da PRF (2015).

\section{Desempenho da segurança viária das rodovias federais inseridas em centros urbanos do Estado do Paraná}

No Estado Paraná, em segmentos urbanos de 15 rodovias federais, sob jurisdição da Polícia Rodoviária Federal, 8.600 pessoas morreram ou sofreram lesões graves, de 2010 a 2014. Acidentes nas BRs-116, 277, 369, 376 e 476 provocaram mais de 7.500 das vítimas. A Tabela 1 apresenta, para cada uma dessas rodovias, os principais segmentos críticos e o número de vítimas nesse período.

Tabela 1 - Trechos críticos das rodovias federais em áreas urbanas no Estado do Paraná

\begin{tabular}{|c|c|c|c|c|}
\hline \multirow{2}{*}{ BR } & \multicolumn{2}{|c|}{ Trechos críticos } & \multirow{2}{*}{$\begin{array}{l}\text { Óbitos e feridos } \\
\text { graves }\end{array}$} & \multirow{2}{*}{ Cidades } \\
\hline & km inicial & km final & & \\
\hline 116 & 120 & 130 & 231 & Fazenda Rio Grande \\
\hline 277 & 720 & 730 & 299 & Foz do Iguaçu \\
\hline 369 & 150 & 160 & 263 & Londrina/Cambé \\
\hline 376 & 170 & 180 & 357 & Maringá \\
\hline 476 & 120 & 130 & 280 & Curitiba \\
\hline
\end{tabular}

Fonte: elaborada pelos autores com base em dados da PRF (2015).

A Pesquisa CNT de Rodovias classificou como "bom" o estado geral dessas rodovias na maioria dos anos. A BR-476 foi a exceção, pois apresentou condições "regulares". A Tabela 2 detalha a classificação de cada uma das cinco rodovias, por ano.

Tabela 2 - Classificação de rodovias federais no Estado do Paraná, de 2010 a 2014

\begin{tabular}{llllll}
\hline BR & \multicolumn{5}{c}{ Ano } \\
\cline { 2 - 6 } & $\mathbf{2 0 1 4}$ & $\mathbf{2 0 1 3}$ & $\mathbf{2 0 1 2}$ & $\mathbf{2 0 1 1}$ & $\mathbf{2 0 1 0}$ \\
\hline $\mathbf{1 1 6}$ & Ótimo & Ótimo & Bom & Bom & Bom \\
$\mathbf{2 7 7}$ & Bom & Ótimo & Bom & Bom & Bom \\
$\mathbf{3 6 9}$ & Bom & Bom & Bom & Bom & Bom \\
\hline
\end{tabular}




\begin{tabular}{cccccc}
\hline \multirow{2}{*}{ BR } & \multicolumn{5}{c}{ Ano } \\
\cline { 2 - 5 } & 2014 & 2013 & 2012 & 2011 & 2010 \\
\hline 376 & Bom & Bom & Bom & Bom & Bom \\
476 & Regular & Regular & Regular & Regular & Regular \\
\hline
\end{tabular}

Fonte: CNT $(2010,2011,2012,2013,2014)$.

Destaca-se que a classificação do estado geral refletiu uma melhor avaliação das condições do pavimento e da sinalização. Em relação à geometria, a BR-476 foi classificada como "ruim", e as demais, como "regulares".

Na Região Metropolitana de Curitiba, no trecho da BR-116 entre os quilômetros 120 e 130, no quais a rodovia atravessa a cidade de Fazenda Grande, 231 pessoas morreram ou ficaram gravemente feridas em acidentes de trânsito, de 2010 a 2014. Nos 30 km da BR-476 situados na área urbana da capital do Estado, classificados como "regulares" em relação ao estado geral das condições da rodovia (CNT, 2010, 2011, 2012, 2013, 2014), cerca de 600 pessoas morreram ou ficaram gravemente feridas, nesse mesmo período. 0 segmento entre os quilômetros 120 e 130, em Curitiba, foi o mais crítico da rodovia no Estado, no qual os acidentes de trânsito fizeram 280 vítimas.

Na BR-277, o trecho urbano mais crítico estava entre os quilômetros 720 e 730, em Foz do Iguaçu, segmento com cerca de 300 vítimas, de 2010 a 2014. A Pesquisa CNT de Rodovias apontou que esse segmento estava em boas condições no que se refere à infraestrutura de engenharia. Na BR-369, rodovia também em boas condições em relação ao estado geral de infraestrutura, houve, nesse mesmo período, 263 vítimas com lesões graves ou fatais no trecho em Londrina e Cambé, entre os quilômetros 150 e 160.

A BR-376 apresentou trecho crítico entres os quilômetros 170 e 190, nas cidades de Maringá e Sarandi, com quase 600 vítimas, de 2010 a 2014. Em 2014, após o início da operação do Contorno Norte da rodovia em Maringá, 11 pessoas morreram ou se lesionaram gravemente no anel rodoviário e outras 125 foram vítimas no antigo trecho, praticamente o mesmo número dos anos anteriores. A Figura 4 destaca o segmento entre os quilômetros 170 e 180 da rodovia, o mais crítico, com 357 vítimas nesse mesmo período, em todo o Estado do Paraná.

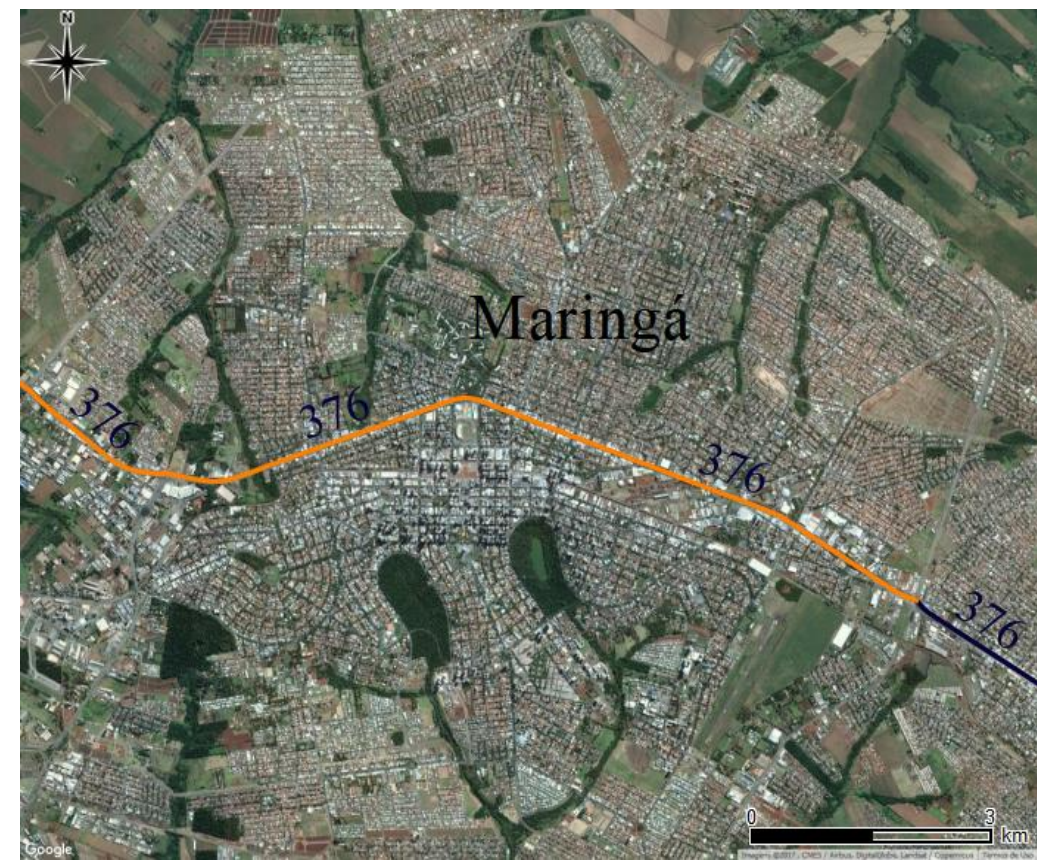

Figura 4 - Trecho urbano crítico da BR-376, que atravessa a cidade de Maringá. Fonte: DNIT (2015).

De acordo com Elvik et al. (2015), tanto o número total de acidentes quanto o número de feridos decrescem após a construção de anéis viários, o que se aplica tanto na via antiga quanto no novo desvio de rota. A variação dos impactos dos anéis viários com o número de acidentes depende, entretanto, de outras variáveis, como 
distribuição do tráfego e o volume de tráfego. Cena et al. (2011) alertam que o aumento do limite de velocidade na nova rodovia também aumenta a preocupação com a severidade dos acidentes.

\section{Desempenho da segurança viária das rodovias federais inseridas em centros urbanos do Estado de Santa Catarina}

Em Santa Catarina, das 8.556 vítimas, a maior parte acidentou-se nas rodovias BRs-101, 282 e 470, nas quais os acidentes nos segmentos urbanos fizeram mais de 7 mil vítimas. A Tabela 3 mostra os segmentos críticos no Estado e o número de vítimas no período de 2010 a 2014.

Tabela 3 - Trechos críticos das rodovias federais em áreas urbanas no Estado de Santa Catarina

\begin{tabular}{|c|c|c|c|c|}
\hline \multirow{2}{*}{ BR } & \multicolumn{2}{|c|}{ Trechos críticos } & \multirow{2}{*}{$\begin{array}{c}\text { Óbitos e feridos } \\
\text { graves }\end{array}$} & \multirow{2}{*}{ Cidades } \\
\hline & km inicial & km final & & \\
\hline 101 & 110 & 120 & 227 & Navegantes/Itajaí \\
\hline 101 & 130 & 140 & 202 & Balneário Camboriú \\
\hline 101 & 190 & 200 & 300 & Biguaçu/São José \\
\hline 101 & 200 & 210 & 680 & São José \\
\hline 101 & 210 & 220 & 484 & São José/Palhoça \\
\hline 280 & 50 & 60 & 218 & Guaramirim \\
\hline 282 & 0 & 10 & 293 & Florianópolis/São José \\
\hline 470 & 50 & 60 & 227 & Blumenau \\
\hline 470 & 60 & 70 & 275 & Blumenau/Indaial \\
\hline
\end{tabular}

Fonte: elaborada pelos autores com base em dados da PRF (2015).

Na BR-101, destacam-se negativamente os trechos dos quilômetros 110 a 150, nas cidades de Itajaí, Balneário Camboriú e Itapema, e 190 a 220, que atravessam as cidades de Biguaçu, São José e Palhoça. Entre os quilômetros 200 e 210 da BR-101, destacados na Figura 5, em São José, coincidente com a BR282 e próximo a Florianópolis, 680 pessoas morreram ou ficaram gravemente feridas entre os anos de 2010 a 2014.

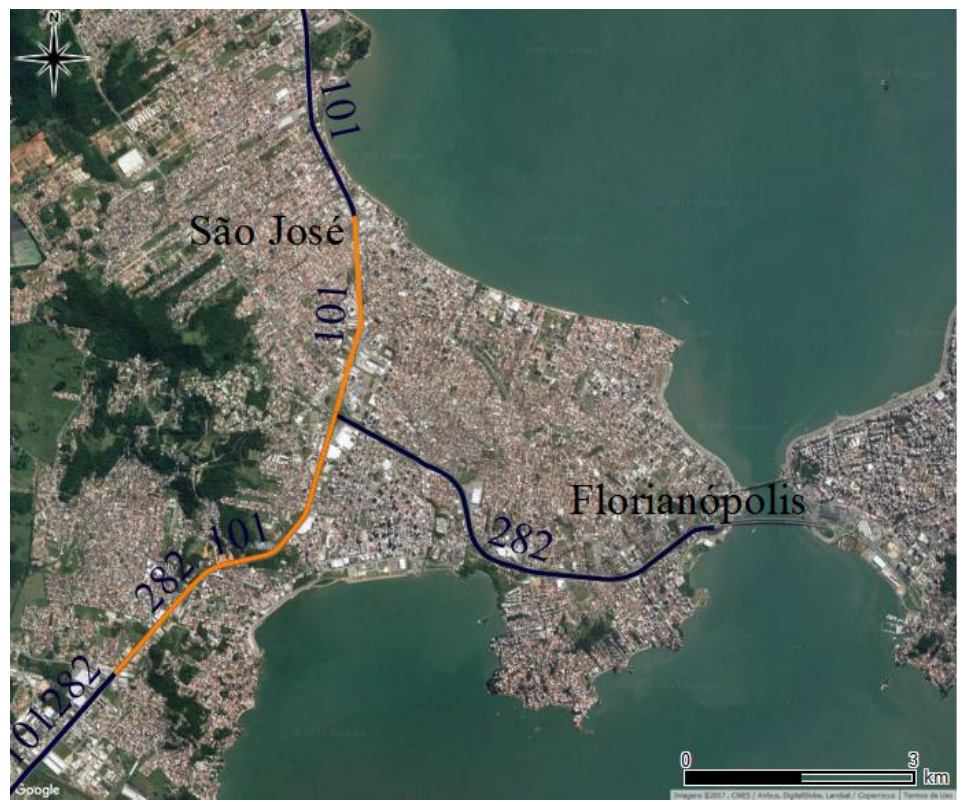

Figura 5 - Trecho urbano das BRs-101 e 282, em São José/SC. Fonte: DNIT (2015).

Em Guaramirim, cidade com cerca de 40 mil habitantes (IBGE, 2017), entre Joinville e Jaraguá do Sul, a BR-280 apresentou um trecho com grande quantidade de vítimas, mais de 200 no período de 2010 a 2014. Na BR-470, o segmento que atravessa as cidades de Blumenau e Indaial possuiu também grande 
número de vítimas graves e mortos em acidentes, principalmente entre os quilômetros 60 e 70, nos quais os acidentes provocaram 275 vítimas nesse mesmo período.

Os estados gerais das rodovias, de acordo com a Pesquisa CNT de Rodovias, variavam, de 2010 a 2014, como "bons" e "regulares", conforme a Tabela 4, apresentando, assim, classificações inferiores àquelas das rodovias federais abordadas no Paraná.

Tabela 4 - Classificação de rodovias federais no Estado de Santa Catarina, de 2010 a 2014

\begin{tabular}{cccccc}
\hline BR & \multicolumn{5}{c}{ Ano } \\
\cline { 2 - 6 } & $\mathbf{2 0 1 4}$ & $\mathbf{2 0 1 3}$ & $\mathbf{2 0 1 2}$ & $\mathbf{2 0 1 1}$ & $\mathbf{2 0 1 0}$ \\
\hline $\mathbf{1 0 1}$ & Bom & Ótimo & Bom & Ótimo/Bom & Bom \\
$\mathbf{2 8 0}$ & Bom & Bom & Regular & Regular & Bom \\
$\mathbf{2 8 2}$ & Regular & Regular & Regular & Bom & Regular \\
$\mathbf{4 7 0}$ & Regular & Regular & Regular & Bom & Regular \\
\hline
\end{tabular}

Fonte: CNT $(2010,2011,2012,2013,2014)$.

O segmento apontado como mais crítico, da BR-101, em São José, continha boas condições de infraestrutura de engenharia, avaliado como "bom" em relação à geometria, à sinalização e à pavimentação (CNT, 2010, 2011, 2012, 2013, 2014). Na BR-280, em Guaramirim, a geometria foi classificada, em 2014, como "regular", apesar do estado geral "bom", registrado pela pesquisa.

\section{Desempenho da segurança viária das rodovias federais inseridas em centros urbanos do Estado do Rio Grande do Sul}

No Rio Grande do Sul, mais de 1.400 pessoas se vitimaram em acidentes na BR-116, o que representa cerca de $34 \%$ das 4.349 pessoas mortas ou gravemente feridas de 2010 a 2014, nos trechos urbanos das rodovias federais em todo o Estado. Os trechos urbanos mais críticos e o número de vítimas nesse período estão expostos na Tabela 5.

Tabela 5 - Trechos críticos das rodovias federais em áreas urbanas no Estado do Rio Grande do Sul

\begin{tabular}{ccccc}
\hline BR & \multicolumn{2}{c}{ Trechos críticos } & \multirow{2}{*}{$\begin{array}{c}\text { Óbitos e feridos } \\
\text { graves }\end{array}$} & Cidades \\
\cline { 2 - 4 } & $\mathbf{k m}$ inicial & $\mathbf{k m}$ final & 221 & Novo Hamburgo/São Leopoldo \\
116 & 240 & 250 & 213 & Sapucaia do Sul/Esteio \\
\hline
\end{tabular}

Fonte: elaborada pelos autores com base em dados da PRF (2015).

O segmento de maior ocorrência situou-se entre os quilômetros 240 e 250, em Novo Hamburgo e São Leopoldo, com 221 vítimas no período entre 2010 e 2014 . A Figura 6 destaca o trecho dos quilômetros 236 a 263 , no qual mais de 400 pessoas sofreram acidentes graves ou fatais. 


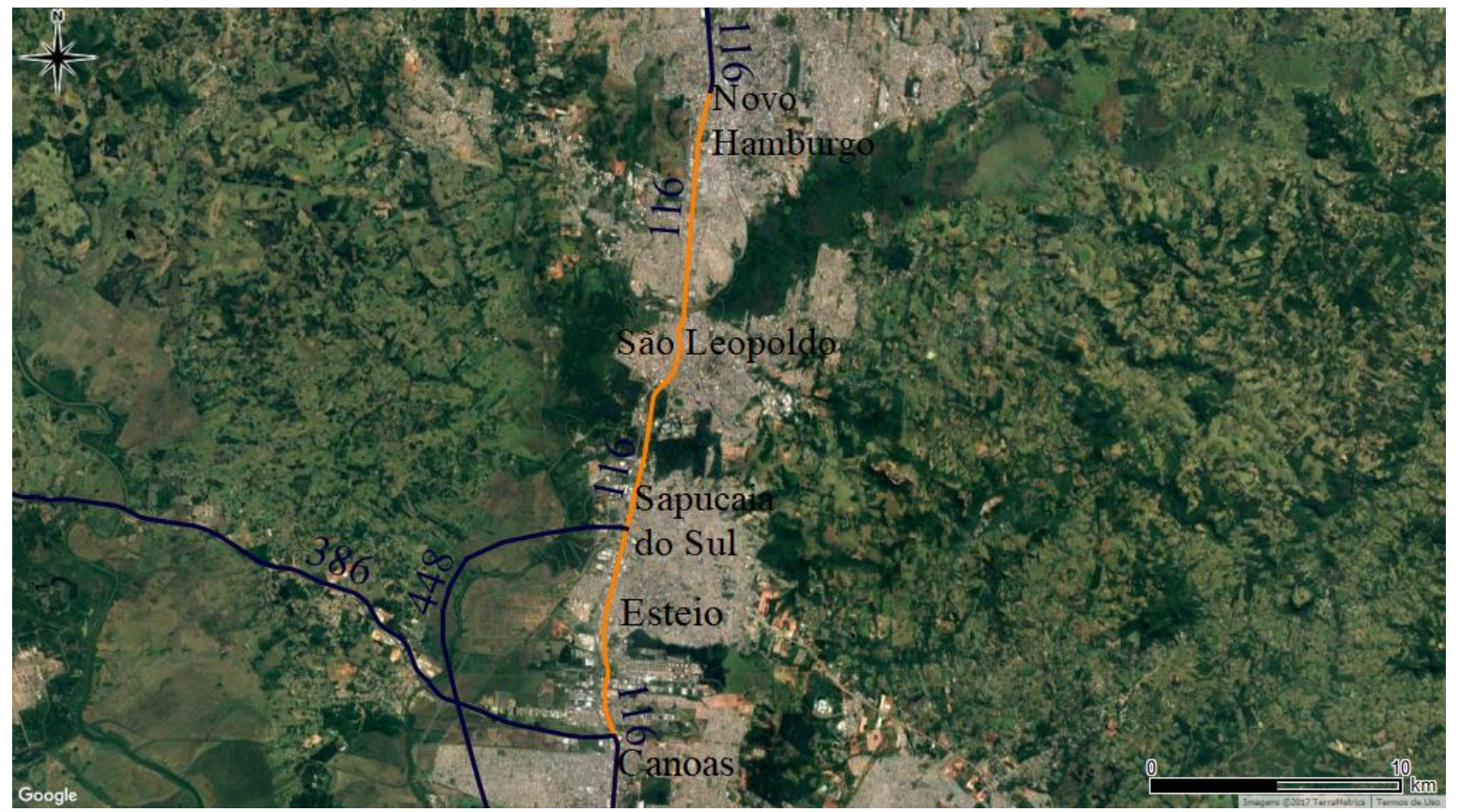

Figura 6 - Trecho urbano da BR-1 16, nas cidades de Novo Hamburgo, São Leopoldo, Sapucaia do Sul, Esteio e Canoas. Fonte: DNIT (2015).

A rodovia BR-116 apresentava, em 2014, condição geral "regular" com relação à geometria, à sinalização e à pavimentação, de acordo com a Pesquisa CNT de Rodovias (CNT, 2010, 2011, 2012, 2013, 2014) e a Tabela 6. Nos anos anteriores, o estado geral era classificado como "bom". A geometria, para todos os anos, foi classificada como "regular". Entretanto, o trecho apontado destacado, próximo à capital Porto Alegre, estava em "ótimas" condições, segundo a Pesquisa CNT de Rodovias.

Tabela 6 - Classificação da rodovia federal BR-116, no Estado do Rio Grande do Sul

\begin{tabular}{cccccc}
\hline \multirow{2}{*}{ BR } & \multicolumn{5}{c}{ Ano } \\
\cline { 2 - 6 } & 2014 & 2013 & 2012 & 2011 & 2010 \\
\hline 116 & Regular & Bom & Bom & Bom & Bom \\
\hline
\end{tabular}

Fonte: CNT $(2010,2011,2012,2013,2014)$.

\section{Conclusões}

Trechos urbanos de rodovias federais têm se mostrado inseguros, com grande número de acidentes e, consequentemente, de vítimas, sobretudo graves e fatais. Embora ofereçam alternativas para deslocamentos urbanos, colaboram para a insegurança viária no país. Constituem-se também em desafio para a operação de transportes em áreas urbanas cada vez mais congestionadas, problema que se reflete em Curitiba, no Paraná, e em São José e Palhoça, em Santa Catarina.

Não há, contudo, na análise dos segmentos urbanos com maior acidentalidade no Sul do país, segundo o método aqui utilizado, evidências de relação direta do número de vítimas graves e óbitos com a baixa qualidade de padrões de engenharia das rodovias. Muitos desses segmentos, nos três Estados abordados, possuem velocidade máxima reduzida de 60 a $80 \mathrm{~km} / \mathrm{h}$. Apesar de se verificar na literatura a necessidade de melhor infraestrutura para pedestres, por exemplo, como a construção de calçadas e passarelas mais próximas, o estado geral de algumas rodovias foi classificado como "ótimo" ou "bom", mesmo nos trechos críticos, como na BR-116, no Rio Grande do Sul, e na BR-101, em São José, em Santa Catarina. Esse trecho catarinense, inclusive, apresenta a pior situação de toda a malha analisada. 
Característica comum entre os pontos é a proximidade com grandes centros urbanos. Além das metrópoles Curitiba e Porto Alegre, as cidades de Florianópolis, Blumenau, Joinville, Londrina e Maringá são classificadas como capitais regionais pelo IBGE (2007). Todas constituem grandes aglomerações urbanas, sendo caracterizadas pelo tamanho e pela densidade da população, pelo grau de urbanização e coesão interna da área, dada pelos deslocamentos da população para trabalho e estudo (IBGE, 2007). Nesses segmentos, portanto, esses movimentos, sejam locais, sejam de passagem, gerados por atividades econômicas e educacionais, aumentam o volume e a exposição ao tráfego, o que, provavelmente, concorra para o agravamento da situação.

Entretanto, de acordo com métodos mais modernos de gestão de trânsito, como aqueles previstos para um Sistema Seguro (Safe System), se nem todos os acidentes podem ser evitados, deve-se prevenir sua gravidade. Essa prevenção pode ser alcançada por maior fiscalização da velocidade máxima permitida e por uma gestão de segurança viária direcionada para os usuários mais vulneráveis do trânsito, os pedestres e os motociclistas, que são as maiores vítimas de acidentes atualmente. Contudo, a fiscalização e a gestão das rodovias federais são de competência dos órgãos federais, o que dificulta a atuação dos municípios. Um transporte coletivo urbano mais eficiente, que proporcione opções para os deslocamentos cotidianos da população, é também essencial na maioria das cidades brasileiras para a mitigação do problema.

A infraestrutura deve ser melhorada, principalmente em relação aos aspectos da geometria viária, como a presença de acostamentos, alças com dimensões adequadas e interseções em desnível. Na verificação das condições rodoviárias, apesar de o estado geral possuir condições satisfatórias, a geometria tinha as piores classificações, o que poderia justificar o grande número de óbitos e de vítimas graves.

Assim, apenas com o aprimoramento da infraestrutura e uma gestão urbana adequada, na qual a segurança seja prioritária e que propicie um transporte urbano com qualidade, pode-se alcançar no Brasil um sistema de transportes realmente seguro, com a consequente redução do número de acidentes e de vítimas, proposta pela Década de Ação pela Segurança no Trânsito 2011-2020.

\section{Referências}

Alburquerque, T. P., Castro, A. A. B. C., Freitas, P. V. N., \& Silva, J. A. R. (2015). Análise da relação entre acessibilidade e acidentes de trânsito em rodovias urbanas: estudo de caso da BR-230 na cidade de João Pessoa PB. In Anais do XXIX Congresso de Pesquisa e Ensino em Transportes (pp. 2829-2839). Ouro Preto: Associação Nacional de Ensino e Pesquisa em Transportes.

Bastos, J. T., Ferraz, A. C. P., Vieira, H., \& Bezerra, B. S. (2012). Geografia da mortalidade no trânsito no Brasil. Revista ANTT, 4(1-2), 24-35.

Bergamasch, I. R. B. (2014). A geografia dos acidentes de trânsito na Região Metropolitana da Grande Vitória (RMGV) - ES, entre 2005 e 2013. 2014 (Dissertação de mestrado). Centro de Ciências Humanas e Naturais, Universidade Federal do Espírito Santo, Vitória.

Brasil. Ministério da Saúde - MS. Coordenação-Geral de Informações e Análises Epidemiológicas. Secretaria de Vigilância à Saúde. Sistema de Informações sobre Mortalidade - SIM. (2015). Datasus. Recuperado em 6 de janeiro de 2015, de http://tabnet.datasus.gov.br/cgi/deftohtm.exe?sim/cnv/obt10uf.def.

Carmo, C. L., \& Raia, A. A. Jr (2016). Segurança viária em trechos urbanos de rodovias federais no estado de São Paulo, Brasil. In Anais do VII Congresso Luso Brasileiro para o Planejamento Urbano, Regional, Integrado e Sustentável: Pluris: contrastes, contradições, complexidades: desafios urbanos no Século XXI (pp. 1-12). Maceió: PLURIS.

Cena, L. G., Keren, N., Li, W., Carriquiry, A. L., Pawlovich, M. D., \& Freeman, S. A. (2011). A Bayesian assessment of the effect of highway bypasses in Iowa on crashes and crash rate. Journal of Safety Research, 42(4), 241-252. http://dx.doi.org/10.1016/j.jsr.2011.05.007. PMid:22017826. 
Confederação Nacional do Transporte - CNT, Serviço Social do Transporte - SEST, Serviço Nacional de Aprendizagem do Transporte - SENAT. (2010). Pesquisa CNT de rodovias 2010: relatório gerencial. 2010 (pp. 273). Brasília: CNT: SEST: SENAT.

Confederação Nacional do Transporte - CNT, Serviço Social do Transporte - SEST, Serviço Nacional de Aprendizagem do Transporte - SENAT. (2011). Pesquisa CNT de rodovias 2011: relatório gerencial. 2011 (pp. 328 ). Brasília: CNT: SEST: SENAT.

Confederação Nacional do Transporte - CNT, Serviço Social do Transporte - SEST, Serviço Nacional de Aprendizagem do Transporte - SENAT. (2012). Pesquisa CNT de rodovias 2012: relatório gerencial. 2012 (pp. 408$).$ Brasília: CNT: SEST: SENAT.

Confederação Nacional do Transporte - CNT, Serviço Social do Transporte - SEST, Serviço Nacional de Aprendizagem do Transporte - SENAT. (2013). Pesquisa CNT de rodovias 2013: relatório gerencial. 2013 (pp. 389 ). Brasília: CNT: SEST: SENAT.

Confederação Nacional do Transporte - CNT, Serviço Social do Transporte - SEST, Serviço Nacional de Aprendizagem do Transporte - SENAT. (2014). Pesquisa CNT de rodovias 2014: relatório gerencial. 2014 (pp. 388). Brasília: CNT: SEST: SENAT.

Departamento Nacional de Trânsito - Denatran. (2017). Frota de veículos. Recuperado em 30 de agosto de 2017, de http://www.denatran.gov.br/estatistica/237-frota-veiculos.

Departamento Nacional de Infraestrutura de Transportes - DNIT (2014). Atlas e mapas: shapefiles. Recuperado em 31 de maio de 2015, de http://www.dnit.gov.br/mapas-multimodais/shapefiles.

Departamento Nacional de Infraestrutura de Transportes - DNIT (2015). Estatísticas de acidentes. Recuperado em 7 de janeiro de 2015, de http://www.dnit.gov.br/rodovias/operacoes-rodoviarias/estatisticas-de-acidentes.

Diesel, L. E. (2005). SIG na prevenção a acidentes de trânsito (Dissertação de mestrado). Universidade Federal de Santa Catarina, Florianópolis.

Elvik, R., Høye, A., Vaa, T. \& Sørensen, M. (2015). O Manual de Medidas de Segurança Viária. Madri: Fundación MaPFRE $1071 \mathrm{p}$.

Ferrer, A. (2017). Movilidad urbana segura. Revista dos Transportes Públicos, 145, p. 7-18.

Freire, L. H. C. V. (2003). Análise de tratamentos adotados em travessias urbanas - rodovias arteriais que atravessam pequenas e médias cidades no RS (Dissertação de mestrado). Escola de Engenharia, Universidade Federal do Rio Grande do Sul, Porto Alegre.

Instituto Brasileiro de Geografia e Estatística - IBGE (2007). Região de influência das cidades - 2007. Recuperado em 23 de agosto de 2017, de http://biblioteca.ibge.gov.br/visualizacao/livros/liv40677.pdf.

Instituto Brasileiro de Geografia e Estatística - IBGE (2015). Projeção da população do Brasil e das Unidades da Federação. Recuperado em 6 de janeiro de 2015, de http://www.ibge.gov.br/apps/populacao/projecao/.

Instituto Brasileiro de Geografia e Estatística - IBGE (2017). Estimativas populacionais para os municípios brasileiros em 01.07.2014. Recuperado em 1 de julho de 2017, de

http://ww2.ibge.gov.br/home/estatistica/populacao/estimativa2014/estimativa_dou.shtm.

International Transport Forum - ITF (2016). Zero Road Deaths and Serious Injuries: Leading a Paradigm Shift to a Safe System. Paris: OECD Publishing. http://dx.doi.org/10.1787/9789282108055-en

Jiang, Y., \& Peng, Q. (2012). The relationship between highways and urban roads in urbanization. CICTP, 2012, 99104.

Johansson, R. (2008). Implementing a policy for traffic safety. Safety Science, 47(6), 826-831.

http://dx.doi.org/10.1016/j.ssci.2008.10.023.

Lima, I. M. O., Figueiredo, J. C., Morita, P. A., \& Gold, P. (2008). Fatores condicionantes da gravidade dos acidentes de trânsito nas rodovias brasileiras (Texto para discussão, No. 1344). Brasília: IPEA. 
Meneses, F. A. B. (2001). Análise e Tratamento de Trechos Rodoviários Críticos em Ambientes de Grandes Centros Urbanos (Dissertação de mestrado). COPPE, Universidade Federal do Rio de Janeiro, Rio de Janeiro.

Peña, C. C. (2011). Análise da segurança viária em interseções nas rodovias federais de Santa Catarina (Dissertação de mestrado). Universidade Federal de Santa Catarina, Florianópolis.

Polícia Rodoviária Federal - PRF. (2015). Estatística de Acidentes nas Rodovias Federais. Brasília: PRF.

Raia, A. A. Jr. (2009) A responsabilidade pelos acidentes de trânsito segundo a visão zero. Revista dos Transportes Públicos, 121, 7-18.

Salvador, D. M., \& Goldner, L. G. (2009). Análise dos tipos de acidentes de trânsito nos trechos duplicado e não duplicado da BR-101 em Santa Catarina. In Congresso Brasileiro de Rodovias \& Concessões 2009 (Vol. 1, pp. 1-12). São Paulo: Associação Brasileira de Concessionárias de Rodovias.

Schmitz, A. (2011). Proposta Metodológica baseada em GIS para análise de segmentos críticos de rodovia: estudo de caso na BR-285/RS (Dissertação de Mestrado). Programa de Pós-graduação em Engenharia Civil, Universidade Federal de Santa Catarina, Florianópolis.

Schmitz, A., \& Goldner, L. G. (2010). Proposta metodológica baseada em GIS para análise de segmentos críticos de rodovia - Estudo de caso na BR - 285. In Anais do XVI Congreso Panamericano de Ingeniería de trânsito, transporte e logística - PANAM. Lisboa: CESUR, IST, Universidade Técnica de Lisboa.

Silva, S. B. Jr (2006). Rodovias em áreas urbanizadas e seus impactos, na percepção dos pedestres. (Dissertação de Mestrado). Universidade Federal de São Carlos, São Carlos.

Silva, S. B. Jr, \& Ferreira, M. A. G. (2008). Rodovias em áreas urbanizadas e seus impactos na percepção dos pedestres. Revista Sociedade e Natureza, 20(1), 221-237. http://dx.doi.org/10.1590/S1982-45132008000100015.

Velloso, M. S., \& Jacques, M. A. P. (2012). On-the-spot study of pedestrian crashes on Brazilian Federal District rural highways crossing urban areas. Transportation Research Part F: Traffic Psychology and Behaviour. 15(5), 588-599.

Velloso, M. S., Jacques, M. A. P., \& Lindau, L. A. (2008). Investigação dos fatores contribuintes de atropelamento de pedestres em rodovias inseridas em áreas urbanas. In Anais do XXII Congresso de Pesquisa e Ensino em Transportes (pp. 1543-1554). Rio de Janeiro: Associação Nacional de Ensino e Pesquisa em Transportes.

United Nations - UN. (2010). 64/255: Improving global road safety. Nova Iorque: UN. Recuperado em 25 de abril de 2017, de http://www.un.org/en/ga/search/view_doc.asp?symbol=A/RES/64/255.

United Nations - UN (2015). New Sustainable Development Agenda. Nova Iorque: UN. Recuperado em 22 de fevereiro de 2017, de http://www.un.org/ga/search/view_doc.asp?symbol=A/RES/70/1\&Lang=E.

World Health Organization - WHO. (2009). Global status report on road safety: time for action. Genebra: Organização Mundial da Saúde.

World Health Organization - WHO. (2013). Global status report on road safety 2013: supporting a decade of action. Genebra: Organização Mundial da Saúde.

World Health Organization - WHO. (2015). 2nd Global High-Level Conference on Road Safety. Brasília. Recuperado em 22 de fevereiro de 2017, de http://www.who.int/roadsafety/events/2015/brasilia_conference/en/.

World Health Organization - WHO. United Nations Road Safety Collaboration. (2017). Global Plan for the Decade of Action for Road Safety 2011-2020. Recuperado em 25 de abril de 2017, de http://www.who.int/roadsafety/decade_of_action/plan/en/.

Editor: Fábio Duarte

Recebido: Set. 21, 2017

Aprovado: Dez. 01, 2018 